\title{
O DIREITO À MORADIA NAS CIDADES SOB A PERSPECTIVA CAMPONESA: UMA REFLEXÃO ATRAVÉS DA RESISTÊNCIA INDIVIDUAL E EM GRUPO
}

\section{The right to housing in the city under the peasant perspective: a reflection through individual and group resistance}

Paula Adelaide Mattos Santos Moreira Universidade Federal da Bahia-UFBA

Informações do artigo

Recebido em 23/08/2020 Aceito em 02/09/2020

doi>: https://doi.org/10.25247/2447-861X.2020.n251.p587-602

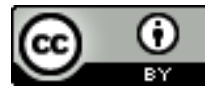

Esta obra está licenciada com uma Licença Creative Commons Atribuição 4.0 Internacional.

\section{Como ser citado (modelo ABNT)}

MOREIRA, Paula Adelaide Mattos Santos. O direito à moradia nas cidades sob a perspectiva camponesa: uma reflexão através da resistência individual e em grupo. Cadernos do CEAS: Revista Crítica de Humanidades. Salvador/Recife, v. 45, n. 251, p. 587-602, set./dez. 2020. DOI: https://doi.org/10.25247/2447-861X.2020.n251.p587-602

\begin{abstract}
Resumo
O presente texto faz parte das reflexões oriundas da tese de doutorado da autora, defendida em 2017, na Universidade Federal da Bahia - UFBA, e inseridas no conjunto da problemática abordada pelo Grupo de Pesquisa GeografAR (PósGeo/ UFBA). Seu objetivo é trazer reflexões sobre o direito à moradia na perspectiva camponesa em seu processo de desterritorialização, quando são obrigados a migrar para as cidades e de reterritorialização, quando tentam imprimir nas cidades seu modo de vida camponês. Como metodologia, aborda-se a questão do rural e urbano no contexto brasileiro e, a partir daí, trata-se da realidade e das estratégias de um camponês isolado, que não e insere num grupo social, porém, luta para manter seu modo de vida e a de um conjunto de camponeses que se insere num grupo social que luta por moradia no contexto da cidade de Salvador. As reflexões advindas a partir dos casos estudados indicam processos de desterritorialização decorrentes do êxodo rural, que são consequentes das perspectivas sociais de inviabilização do acesso à terra. Assim sendo, foram comuns a ambos, situações de sofrimento e, para além deste, de resistência camponesa no meio urbano. Visualiza-se, a partir destes exemplos, que o camponês se prejudica no seu processo de perda territorial, porém estes mesmos sujeitos trazem à tona formas de se reterritorializar a partir da luta pela manutenção de seu modo de vida, mesmo com dificuldades.

Palavras-Chave: Direito à Moradia. Resistência Camponesa. Territorialização e Territorialidades. Relação Rural-Urbano.

\section{Abstract}

This text is part of the reflections arising from the author's doctoral thesis, defended in 2017, at the Federal University of Bahia - UFBA, and inserted in the set of issues addressed by the Geographical Research Group (PósGeo / UFBA). Their objective is to bring reflections on the right to housing from a peasant perspective in their process of deterritorialization, when they are forced to migrate to cities, and of reterritorialization, when they try to print their peasant way of life in cities. As a methodology, the issue of the rural and urban in the Brazilian context is approached and, from there, it deals with the reality and strategies of an isolated peasant, who does not belong to a social group, however, struggles to maintain his way of life. life and that of a group of peasants who are part of a social group that struggles for housing in the context of the city of Salvador. As reflections arising from the cases studied, they indicate processes of deterritorialization resulting from the rural exodus, which are a consequence of the social prospects of making access to land unfeasible. Therefore, there was a commonality of both, chances of suffering and, beyond this, of peasant resistance in the urban environment. It can be seen, from these examples, that the peasant is harmed in his process of territorial loss, however these same subjects bring up ways to reterritorialize themselves from the struggle to maintain their way of life, even with difficulties.

Keywords: Right to Housing. Peasant Resistance. Territorialization and Territorialities. Rural-Urban Relationship.
\end{abstract}




\section{Introdução}

Este artigo traz parte das reflexões vivenciadas na tese de doutorado da autora (MOREIRA, 2017), defendida no Programa de Pós-Graduação em Arquitetura e Urbanismo PPGAU pertencente à Universidade Federal da Bahia - UFBA e, inseridas no conjunto da problemática abordada pelo Grupo de Pesquisa GeografAR (PósGeo/ UFBA). Seu objetivo é trazer reflexões sobre o direito à moradia na perspectiva camponesa em seu processo de desterritorialização, quando são obrigados a migrar para as cidades e, de reterritorialização, quando tentam imprimir nas cidades seu modo de vida camponês. Por esta razão, considerase que este texto esteja enquadrado no Eixo Temático 1 do SINARUB 2020, visto que levanta pontos referentes aos paradigmas compreensivos da relação campo-cidade e rural-urbana, na perspectiva da consideração das ruralidades presentes no meio urbano.

Parte-se do pressuposto da atualidade da questão agrária e da utilização do conceito de campesinato. Stédile (2005) traz que a questão agrária está relacionada ao estudo dos problemas vinculados a concentração da terra $e$, as suas consequências para o desenvolvimento das forças produtivas de uma determinada sociedade. Marcos \& Fabrini (2010) tratam a questão de forma mais ampla, porém, trazem o mesmo sentido para o Brasil, afirmando que a questão agrária está relacionada à existência de um problema estrutural no campo e, que nos países da América Latina, em geral, tal problema se relaciona diretamente com a elevada concentração de terras. Em ambas interpretações, o que se coloca é a relação existente entre o poder e a propriedade privada no contexto da sociedade capitalista.

A partir do pressuposto apresentado, visualizam-se correlações entre a moradia camponesa e a questão agrária. Adentra-se, então, no fato de que o camponês se encontra constantemente no processo de luta por território, passando com frequência por processos de desterritorialização e reterritorialização, ou, melhor dizendo, na construção de sua territorialidade, esta entendida, segundo Saquet (2015), como uma prática espaciotemporal, pluridimensional, efetivada nas relações sociais entre si (de poder) e com a natureza, por meio dos mediadores materiais e imateriais. Tal circunstância, inevitavelmente traz, para o camponês, uma condição precária e pouco estável quanto à sua moradia. Neste sentido, este texto traz o êxodo rural para discutir a questão da moradia camponesa no contexto brasileiro.

A moradia na sua relação com o campesinato está inserida num universo de heterogeneidade, porém, com a nuances específicas. Segundo Woortmann (1990), a ética 
camponesa apresenta terra, trabalho e família como valores morais e categorias intimamente relacionadas entre si, tendendo a gerar configurações peculiares relacionadas ao modo de vida destes grupos. Assim, o labor na terra, ou, a agricultura, traz uma completude do significado de moradia, porque o trabalho ali é essencial para a reprodução de ideal de vida. Neste contexto, a família se reproduz a partir desta moradia, mantendo hábitos peculiares que a caracteriza como um grupo.

Como metodologia, aborda-se a questão do rural e urbano no contexto brasileiro e, a partir daí, trata-se da realidade e das estratégias de um camponês isolado que, não se insere num grupo social, porém, luta para manter seu modo de vida e, a de um conjunto de camponeses que se insere num grupo social que luta por moradia no contexto da cidade de Salvador. Nesta perspectiva, são feitas reflexões quanto a potência de cada uma das formas de resistência camponesa nas cidades, a partir da luta pelo direito à moradia, na perspectiva da manutenção de um modo de vida específico: o modo de vida camponês.

As reflexões advindas a partir dos casos estudados indicam processos de desterritorialização decorrentes do êxodo rural que, são consequentes das perspectivas sociais de inviabilização do acesso à terra. Assim sendo, foi comum a ambos, situações de sofrimento e, para além deste, de resistência camponesa no meio urbano. Visualiza-se a partir destes exemplos, que o camponês se prejudica no seu processo de perda territorial, porém, estes mesmos sujeitos trazem à tona, formas de se reterritorializar a partir da luta pela manutenção de seu modo de vida, mesmo com dificuldades. Tais formas de reterriorialização, tanto na perspectiva de um único sujeito como na de um grupo social, trazem para os estudos urbanísticos, pistas quanto ao mecanismo das práticas profissionais daqueles que atuam na organização de espaços de moradia nas cidades.

\section{A moradia camponesa nas adversidades: êxodo rural, desconstruções e recosntruções da moradia camponesa nas cidades}

Segundo Santos (2005), houve uma inversão do local de residência da população entre os anos de 1940 e 1980. Em 1940, a taxa de urbanização era de 26,35\%, já em 1980, ela passou a 68,86\%. Deve-se considerar, segundo o autor, que neste período, a população brasileira triplicou e, a população urbana multiplicou-se por 7,5. Seguindo esta mesma lógica, segundo dados do IBGE, em 1991 a população urbana era de 75,47\%, em 2000, 81,23\% e em 2010, 
84,36\%. Assim sendo, segundo Santos (2014), houve uma metamorfose do espaço habitado, onde, no Brasil, ocorreu o aparecimento de enormes cidades, pois este crescimento foi acompanhado de uma distribuição desigual da população por regiões.

Wanderley \& Favareto (2013), vão, entretanto, relativizar estes percentuais, afirmando que o IBGE simplifica o conteúdo do que seria urbano e rural, e, por isso, propõem um novo conceito de ruralidade. Neste conceito, eles levantam três questões fundamentais: a) as relações entre os espaços rurais e as cidades assumem, de forma crescente, um caráter de interdependência, superando o antagonismo que marcou sua evolução histórica; b) os traços que distinguem os espaços rurais variam de uma sociedade a outra e, assumem em cada uma delas um sentido particular; c) as múltiplas conflitualidades que intermediam os diversos interesses ligados ao mundo rural (e fora dele) constituem a base da ruralidade que deveria ser considerada no plural, como ruralidades. A confluência destas três questões indica e dá conteúdo ao espaço rural de vida e de trabalho, o que se pode considerar como ruralidade contemporânea. Neste sentido os autores consideram o êxodo rural como uma realidade, porém, em menor escala do que é veiculado. Para eles, a população rural em 2010 seria de $24,3 \%$, enquanto que para o IBGE este número é $15,6 \%$. Para este artigo, são trabalhados os dados do IBGE, já que para este estudo é importante, somente, compreender se as políticas de implantação de assentamentos de reforma agrária impactaram a dinâmica populacional dos municípios. Porém, é importante se considerar que os percentuais trazidos aqui devem ser relativizados, afim de que se tenha uma compreensão mais ampla quanto à redução do rural no país.

A modernização do campo, ocorrida na década de 1970, favoreceu os interesses dos grandes produtores e empresas rurais. Neste processo, afirma Lima et al (2008), ocorreu uma série de fatos que conjuntamente acabaram por excluir os pequenos produtores rurais dos mínimos espaços que ocupavam no campo, dentre estes, pode-se citar: as tecnologias automatizadas, desempregando os agricultores; as monoculturas, uniformizando as produções e subordinando os agricultores as indústrias de insumos e genética; o endividamento, sendo que muitos tiveram que entregar suas propriedades para saldar dívidas; a abertura de novas fronteiras agrícolas, tornado o mercado mais competitivo e estimulando ainda mais a violência no campo. Para piorar a situação, não foram disponibilizados subsídios e incentivos governamentais suficientes aos pequenos produtores. Wanderley e Favareto (2013) complementam, afirmando que o movimento populacional foi 
fruto, principalmente, da ação dos grandes proprietários no sentido de "removerem" de suas terras a presença "desnecessária e arriscada" de trabalhadores moradores e de agricultores que se utilizavam de outras formas de produzir. Assim, segundo Lima et al (2008), estes (os pequenos proprietários, arrendatários, parceiros e posseiros) não tiveram muitas opções, a não ser migrar para as cidades, a procura de emprego, gerando ali uma massa de desempregados. A Figura 1 mostra uma charge que trata desta questão e dispensa comentários.

Figura 1 - Charge sobre Êxodo Rural e Questão Agrária

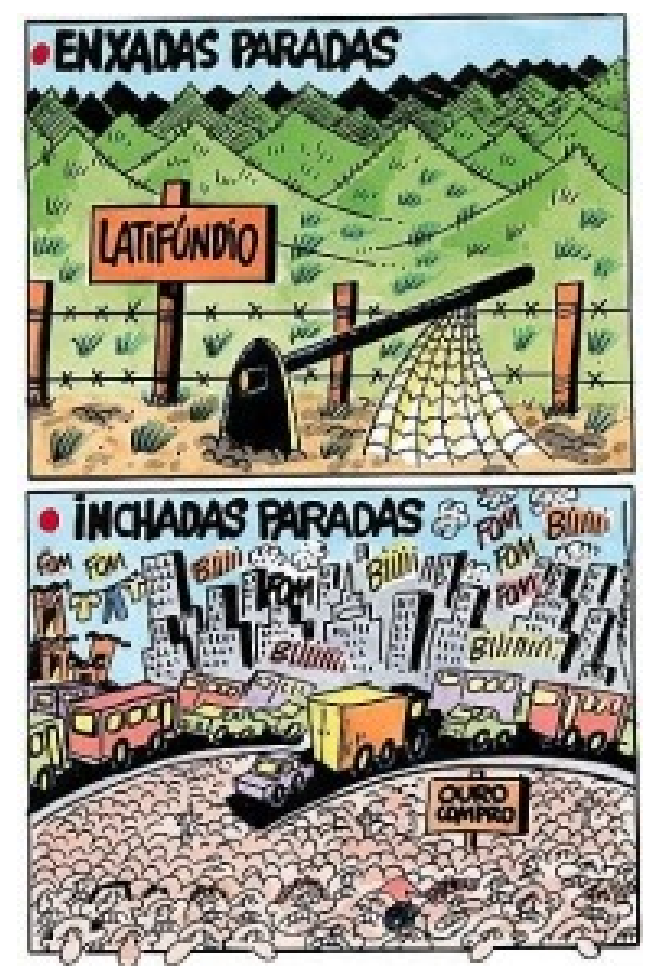

Fonte: autor desconhecido

As migrações em massa do campo para as cidades, o êxodo rural, geram consequências marcantes tanto nas áreas que recebem, quanto nas que perdem população. Nas primeiras, ocorrem desequilíbrios no crescimento de cidades que, na maior parte dos casos, não são absorvidos pela infraestrutura urbana e de moradia, gerando processos de privação pessoal e vulnerabilidade social. Nas áreas de origem, ocorre diminuição da população, fato que gera a perda direta e imediata de sua vitalidade social. Porém, para os que migram, as perdas são devastadoras, pois, segundo Vinholi e Martins (2012), a chegada num novo lugar de moradia, no caso, a cidade, obriga-os a ter que se adaptar bruscamente, 
fazendo-os passar por inúmeras alterações nos modos de vida. Eles são obrigados a se desterritorializar do campo para se reterritorializar na cidade. Além disso, ocorrem rupturas dos laços familiares, já que, na maior parte dos casos, parte da família sai e outra fica, fato que deixam marcas permanentes na memória e, causam traumas e sofrimento.

O pior é se verificar que as condições de vida no campo não tendem a uma melhora condizente com sua demanda. Muito pelo contrário, é no campo que a infraestrutura é menos presente. Junior et al (2006) afirmam que é necessário inovar na política fundiária brasileira, fato que possibilitaria a incursão de jovens no campo, realizando-se profissionalmente. Para tanto, coloca-se como prioridade uma reforma na estrutura agrária que contemple a distribuição de terras, o crédito agrícola, a infraestrutura, a educação do campo, a capacitação, a assistência técnica, o lazer, dentre outros. Porém, não se pode deixar de considerar que as forças políticas e econômicas hegemônicas do país vêm, historicamente, freando qualquer tipo de ação neste sentido.

Diante de tantas adversidades no campo, que vão desde a questão da concentração de terra, à consequente violência, somando-se ao desfavorável cenário agrícola aos pequenos produtores, até a falta de infraestrutura, não é de se admirar que o êxodo rural seja uma realidade que perdure durante tanto tempo. A tendência do êxodo rural na escala nacional, da região Nordeste e da baiana é uma realidade atual. A Tabela 1 mostra que $15,54 \%$ da população brasileira se encontrava no campo em 2010. Eram 29.830.007 pessoas resistindo a todas as adversidades e mazelas para a manutenção da vida no meio rural.

$\mathrm{Na}$ Bahia, este percentual aumenta: $27,93 \%$ da população resistia no campo. Proporção parecida é encontrada na região Nordeste $(26,87 \%)$. No primeiro caso, são 3.914.430 pessoas, quase quatro milhões, que viviam com pouca infraestrutura, em minifúndios (ou posses precárias), com pouca condição de se desenvolver, mas, que estavam ali. Elas ainda não haviam optado pela migração. 
Tabela 1 - População no Brasil, na Região Nordeste e na Bahia, 2010

\begin{tabular}{|c|c|c|c|c|c|}
\hline \multirow{3}{*}{ UNIDADE ESPACIAL } & \multicolumn{5}{|c|}{ POPULAÇÃO } \\
\hline & \multicolumn{2}{|c|}{ RURAL } & \multicolumn{2}{|c|}{ URBANO } & \multirow{2}{*}{$\begin{array}{c}\text { TOTAL } \\
\text { № }\end{array}$} \\
\hline & No & $\%$ & $\mathrm{~N}^{\circ}$ & $\%$ & \\
\hline Bahia & 3.914 .430 & 27,93 & 10.102 .476 & 72,07 & 14.016 .906 \\
\hline Região Nordeste & 14.260 .704 & 26,87 & 38.821 .246 & 73,13 & 53.081 .950 \\
\hline Brasil & 29.830 .007 & 15,64 & 160.925 .792 & 84,36 & 190.755 .799 \\
\hline
\end{tabular}

Fonte: IBGE. Censo, 2010. Elaboração pela autora, 2017.

No contexto dos que resistem no campo, outro aspecto identificado é que onde os movimentos sociais são mais ativos, tende-se a existir uma dinâmica populacional rural mais favorável, porém, este dado não se comporta de forma constante, já que outros fatores também interferem, tais como os processos históricos, a região, o clima, a economia, a vizinhança, a oportunidade, a cultura, dentre outros. Assim, a evasão do camponês de seu local de origem é uma solução que vem a ser predominante aos processos de luta pela terra. Mas, será que estes camponeses que migram deixam de ser camponeses? Será que deixam de querer estar no campo por migrarem para as cidades? Existe resistência camponesa nas cidades? Para refletir tais questões, colocam-se aqui dois exemplos representativos: o de meu avô Joaquim, em Minas Gerais, e de uma comunidade em Salvador.

\section{O caso da resistência e luta por moradia de um único camponês}

A Figura 2 mostra a espacialização da luta e resistência do vovô Joaquim na cidade de Itajubá, localizada na região sul de Minas Gerais entre meados de 1930 e 1980.

O caso de vovô Joaquim é parecido com muitos outros tantos. O jovem nascido na cidade mineira de Delfim Moreira era filho de um ex feitor de escravos (em Parati) e, foi criado no meio rural de Piquete (estado de São Paulo), em conjunto com sua família, praticando a agricultura. Aos 18 anos, foi obrigado a migrar para cidade para servir ao exército, quando participou de importantes embates no contexto da revolução Constitucionalista de 1932. 
Posteriormente, já no contexto pós migração campo-cidade, não tendo sua família mais o acesso à terra própria, foi trabalhar na recém-implantada Fábrica de Armas de Itajubá (atual IMBEL). Ali, iniciou sua carreira como operário na indústria e constituiu sua família. É neste momento que se inicia sua busca incessante e a reprodução fragmentada de seu modo de vida camponês.

Enquanto trabalhava na Fábrica de Armas (até o momento de sua aposentadoria) ele e sua família tinham direito à moradia no bairro de mesmo nome. Neste bairro, se mudaram neste período por três vezes. A Figura 2 mostra onde se localizavam as casas e, o terreno onde vovô Joaquim ocupava informalmente para praticar a atividade agrícola.

Destaca-se que os terrenos, pertencentes ao exército, eram ociosos e nunca houve oposição a sua atividade neles. Percebe-se que todas as vezes que a família se mudava de casa, vovô Joaquim apossava-se de um terreno em sua proximidade. Sua produção se constituía em uma agricultura diversificada (feijão, milho, arroz, legumes, verduras), criação de porcos e de galinhas. Ela era destinada a suprir as necessidades da família (ele a esposa e mais dez filhos) e, o excedente era vendido no bairro.

Num momento posterior, após sua aposentadoria, vovô Joaquim continuou plantando em uma área na Fábrica de Armas, porém, residindo no centro da cidade, já que perdera o direito à moradia no bairro da tal Fábrica. Na área cedida, ele construiu uma casa de taipa onde passava períodos. Esta situação era extremamente conflituosa por dois motivos. Primeiro, porque sua família morava na cidade e ele ficava dividido entre esta e sua vida como camponês. $E$, segundo, porque quando passava períodos com sua família, na cidade, sua roça sofria furtos, fato que o deixava extremamente estressado. Foram mais de cinco anos de sofrimento, de deslocamentos cansativos, quando, já idoso, não teve mais forças para manter tal rotina. Neste momento, ele se articula na própria sede municipal e consegue que um amigo ceda uma área na beira do rio Sapucaí, bem próxima a sua casa, como indica o item 2 da Figura 2. 
Figura 2 - Espacialização de Vovô Joaquim na busca de um local para morar na cidade de Itajubá/MG.

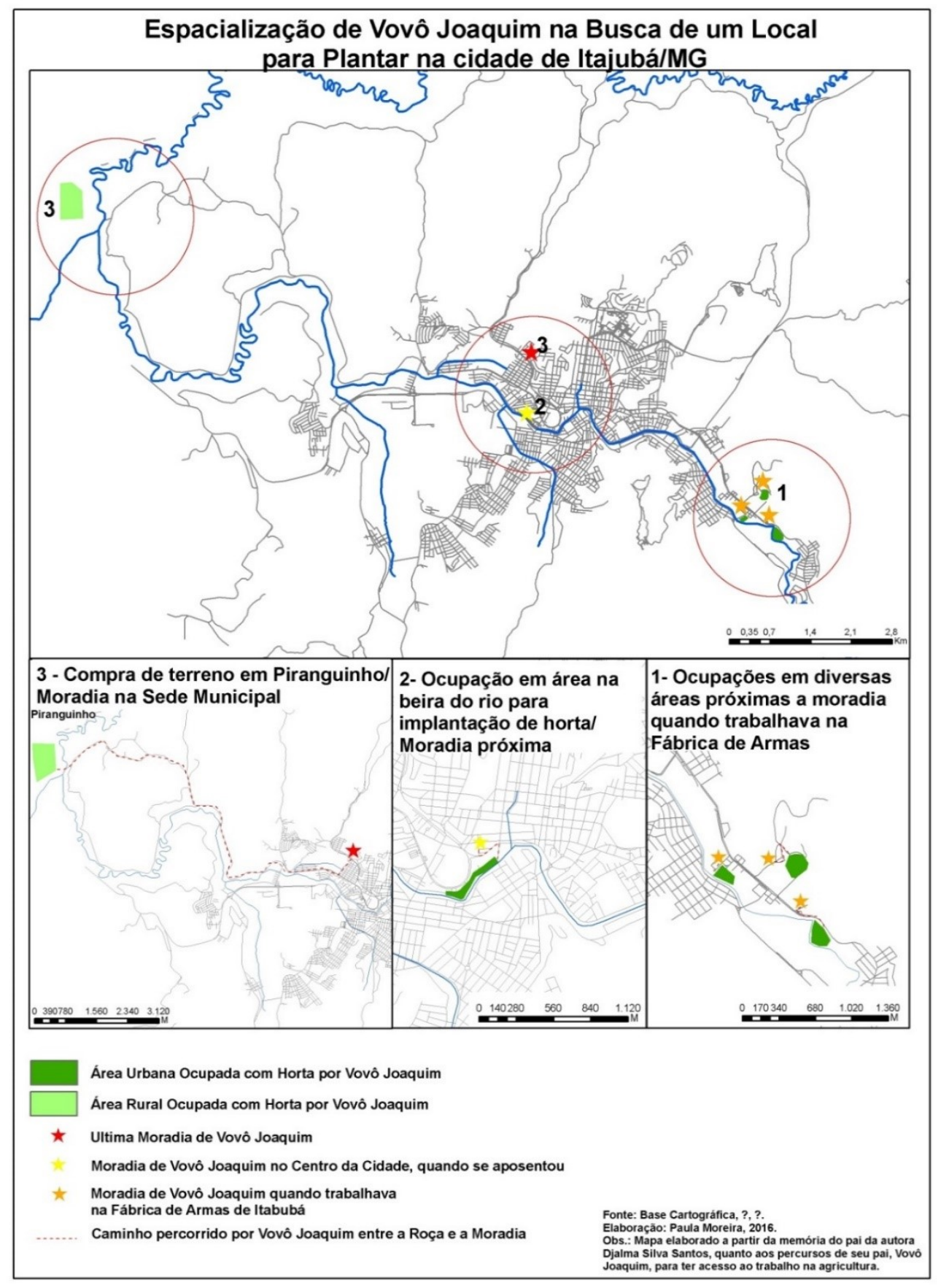

Fonte: Elaborado pela autora, 2016.

Durante dois anos, já com 70 anos, ele se manteve ali, plantando, colhendo, pescando e vendendo seus produtos aos vizinhos. Porém, o fato de estar cultivando na cidade e em Área de Proteção Ambiental - APP, por sua irregularidade em relação à legislação ambiental, gerou grande polêmica, e a Prefeitura não permitiu mais que realizasse tal atividade. 
Consternado com esta situação, porém, ainda com necessidade de estar exercendo sua atividade na agricultura ele, sem recurso financeiro, solicitou a um dos seus filhos que comprasse um terreno num loteamento localizado na área rural do município de Piranguinho, vizinho a Itajubá e distante em 20 km de sua moradia. Então, a partir daí ele entra no terceiro estágio de sua luta para se manter como camponês. Ele adquiriu uma moto e trafegava entre sua casa e o terreno que, assim como na Fábrica de Armas, construiu uma moradia de taipa. Durante cerca de quatro anos ele se dividiu entre a casa da família e o terreno em Piranguinho, até o momento em que não mais suportou esta rotina cansativa e conflituosa, adoeceu e, posteriormente faleceu em 1989, com 76 anos.

Sua vida foi marcada pela resistência camponesa, sempre criando condições para se manter na atividade agrícola, algo que não se separava de seu próprio corpo. Ele era um camponês que foi obrigado a viver na cidade e trabalhar como operário. Tendo sorte em poder ter acesso a áreas de cultivo na Fábrica de Armas, sofreu, posteriormente após este acesso ser dificultado pela distância de sua moradia. Já idoso, lutou até o último momento para manter junto dele o que concebia como elementos fundamentais de sua moradia: a terra, a casa, a família e seu trabalho.

\section{O caso de um grupo de camponeses imigrantes num centro urbano}

O primeiro caso trata da situação de uma única pessoa em sua resistência cotidiana para se manter camponês numa cidade do interior de Minas Gerais. O segundo trata da situação de um conjunto de pessoas que migraram para uma cidade grande, Salvador, de diversas cidades do interior baiano e constituem em um determinado local, no subúrbio soteropolitano, uma comunidade de nome Quilombo Paraíso.

O Quilombo Paraíso, localizado nas bordas da Área de Proteção Ambiental - APA da bacia do rio do Cobre, é fruto de uma ocupação ocorrida, em 2009, com cerca de 450 famílias, lideradas pelo Movimento dos Sem Teto da Bahia (MSTB). Alcântara (2016) afirma que, após conflito com a polícia e tensão junto ao Governo do Estado, permaneceram no Quilombo cerca de 120 famílias. A Figura 3 indica a localização da comunidade e sua implantação no terreno, no ano de 2015. Percebe-se sua conexão com a malha urbana, recém implantada, e, também, a presença de uma vasta área verde desocupada, a citada APA da Bacia do Rio do Cobre. 
A comunidade é formada por pessoas que migraram de diversas regiões do estado da Bahia, em especial do Recôncavo Baiano, e, também, da própria Salvador. A vivência passada com a agricultura, por parte de muitos moradores, assim como a demanda pela mobilização para sustentabilidade ambiental, por causa da localização da ocupação próxima a APA e, os consequentes questionamentos que sofriam, despertou a possibilidade de se fazer uma roça comunitária. De forma organizada e articulada com o MSTB e o Centro de Estudos e Ação Social - CEAS, a comunidade se inseriu, em 2012, segundo Alcântara (2016), numa experiência de produção agroecológica. Tal experiência, afirma a autora, representou uma ação pioneira no contexto soteropolitano, configurando-se como instrumento de resistência política, por provocar discussão e prover proteção contra as ações de devastação e desequilíbrio ambiental no entorno da APA, além de contribuir para a segurança alimentar das famílias.

O que vincula esta experiência ao tema abordado neste texto é que ela não se viabilizaria se não houvesse camponeses que migraram para a cidade na comunidade. Tratase de uma ação de resistência, não somente política, mas, também, de um modo de vida que tentava brotar nas brechas do concreto de uma grande cidade. O conhecimento, o saber, a vontade e o prazer de estar trabalhando a terra na atividade proposta para o grupo, foi assumido, principalmente, por camponeses que migraram para Salvador. Estes, se configuraram como professores, orientadores, animadores, ou, simplesmente, lideranças deste processo.

Acrescentando-se a resistência camponesa e seu importante papel na configuração do grupo, o Quilombo Paraíso traz para o contexto de Salvador a prática da agricultura de forma agroecológica, num contexto coletivo e, num espaço confinado (ver a dimensão da roça na Figura 3).

Sem dúvida, a produção agroecológica traz, para o grupo, um desafio grande que, contribuiu para o processo de construção de coletividades, para o fortalecimento de cada um e para a unidade do conjunto, fatores estes importantes para a luta pela permanência de comunidades que possuem uma condição frágil em relação à posse da terra. 
Figura 3 - Espacialização da Comunidade Quilombo Paraíso, localizada em Salvador/BA

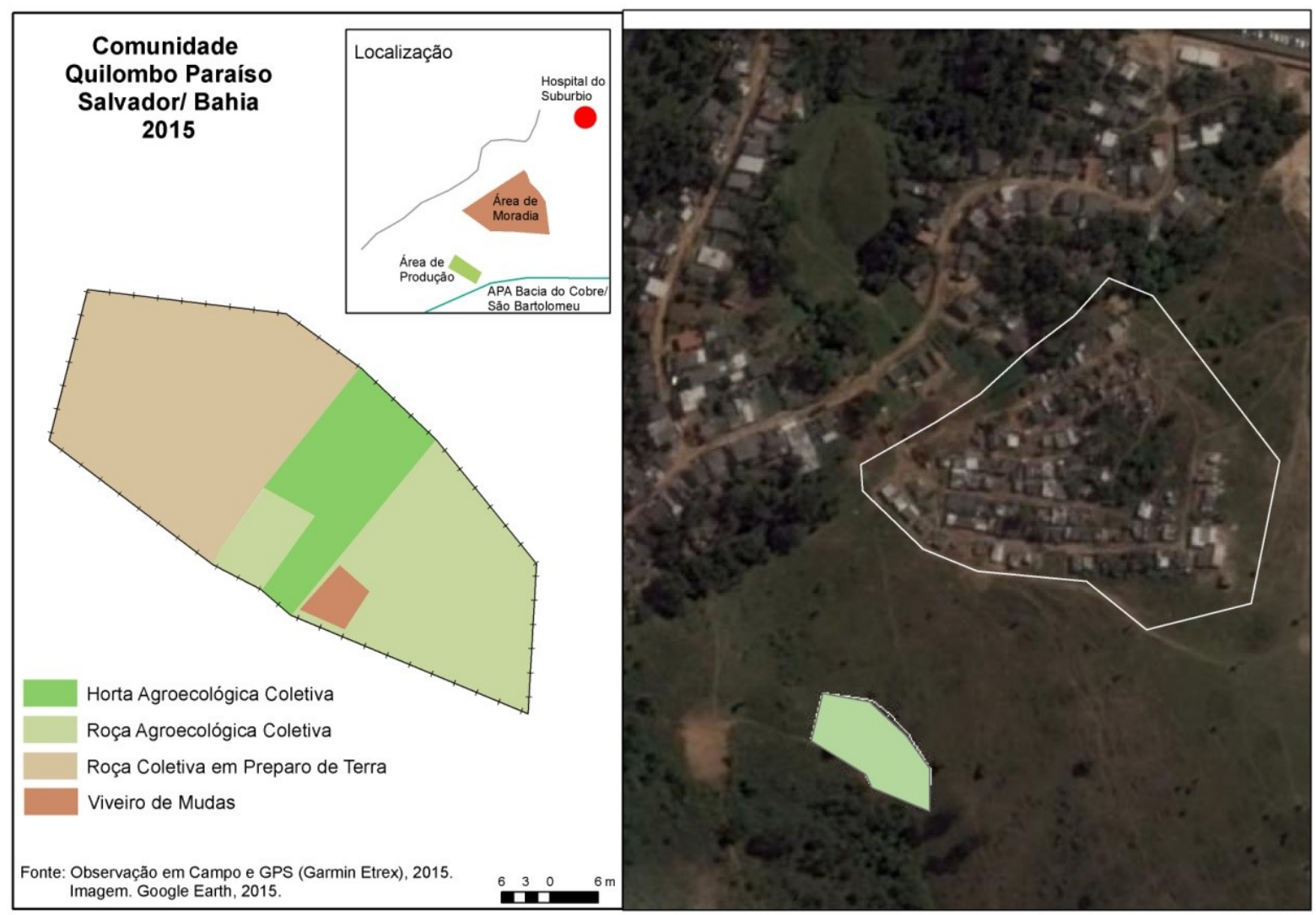

Elaboração: CEAS, 2015 e autora, 2016.

É importante destacar que, plantar coletivamente pode ser algo novo para os camponeses, porém, os movimentos sociais têm experiência em conduzir estes processos num contexto adequadamente político, trazendo reflexões sociais sobre esta prática. Assim, - Quilombo Paraíso representa, tanto a luta por moradia urbana, como traz para estes camponeses a sobrevida reinventada de uma das atividades chave do modo de vida camponês: a agricultura. A agricultura os traz a memória fragmentos de dois valores da ética camponesa, segundo Woortmann(1990): terra e trabalho. Com esta atividade, para muitos, assim como acontecia para vovô Joaquim, esta roça traz uma completude do significado de moradia, porque o trabalho ali é essencial para sua reprodução de ideal de vida. Talvez, uma possibilidade contemporânea de reprodução, mesmo que limitada, de um modo de vida que para muitos dos ali viventes estava sufocado ou esquecido pelo seu distanciamento de suas terras, do campo e do trabalho rural. 
Não se pode deixar de destacar que, o terceiro valor da ética camponesa, a família, foi fundamental para se possibilitar os processos migratórios dos que se estabeleceram no Quilombo Paraíso, principalmente através de algo parecido com a relação familiar de compadrio. Neste sentido, tanto os trabalhos coletivos na agroecologia, como a própria constituição camponesa contribuíram para o fortalecimento das redes de relações da comunidade, afastando-se de esquemas individualistas ou competitivos e, apoiando-se na solidariedade, no companheirismo, ou, melhor, na grande família ali construída no processo de luta.

\section{Considerações finais}

As reflexões oriundas dos casos estudados mostram que a luta e resistência camponesa para manter seu modo de vida está vinculada a sua necessidade de se relacionar com a terra e trabalho, em sua estrutura familiar. Tratando-se, aqui, de casos de processos de desterritorialização advindo do êxodo rural, consequente das perspectivas sociais de inviabilização do acesso à terra, visualiza-se, em ambos os casos, situações de sofrimento e, para além deste, de resistência camponesa no meio urbano.

Assim sendo, visualiza-se a partir destes exemplos, que o camponês se prejudica em desvincular a sua moradia de seu trabalho com a terra, fato comumente ocorrido nas cidades, porém, estes mesmos sujeitos trazem à tona, formas de se reterritorializar a partir da luta pela manutenção de seu modo de vida, mesmo com dificuldades. Tais formas de reterriorialização, tanto na perspectiva de um único sujeito, como na de um grupo social, trazem para os estudos urbanísticos, pistas quanto ao mecanismo das práticas profissionais daqueles que atuam na organização de espaços de moradia nas cidades.

Direcionando-se estas considerações finais a um apanhado de questões que podem vir a indicar caminhos aos estudos urbanísticos, no que se refere a especificidade do público camponês migrante, ou, não, não se pode deixar de iniciar afirmando que para estes, o respeito a sua condição seria o acesso à terra. Assim, a reforma agrária e a regularização fundiária se constituem como algo fundamental e prioritário. O acesso à terra, entretanto deve ser acompanhado de toda política de apoio produtivo, de formação e de infra estruturação do meio rural, baseado na necessidade camponesa. Isto porque, manter o camponês no campo, com qualidade, seria um grande passo no sentido de se combater as 
desigualdades sociais e as deformidades espaciais deste país. Neste sentido, os desafios seriam grandes do ponto de vista técnico urbanístico, porém necessários de serem assumidos.

Os casos tratados, o de vovô Joaquim e da comunidade Quilombo Paraíso, não só ajudam a trazer reflexões quanto as necessidades do público camponês que migra para as cidades, como, através de suas estratégias, apontam alguns caminhos. A questão fundamental é que as cidades necessitam dar abrigo e disponibilizar moradia adequada a seu público, em suas características e diferenças. A moradia camponesa, em sua plenitude, traz o trabalho com a terra e a articulação familiar como alicerces fundamentais. Mas, como isso pode ser reproduzido nas cidades? Através das estratégias adotadas nos dois casos, o ponto chave seria assumir e apoiar ruralidades nos centros urbanos, afastando-se, de fato, da dicotomia estabelecida entre o que seria atividade rural no campo e, urbana, nas cidades.

Assim sendo, políticas e ações que apoiem a implantação de hortas em vazios urbanos (terras públicas ou privadas), quintais produtivos, praças de pomares seriam de grande importância. Neste sentido, aliado a estas ações, já visando a renda camponesa dos imigrantes, seria fundamental o apoio a circulação dos produtos, principalmente com a estruturação de feiras nos bairros. Estas feiras, além de se constituírem no local da venda dos produtos, poderiam ser pensadas, em conjunto com seu público, em locais onde a memória e os valores das pessoas do campo sejam ressaltadas e valorizadas, através da evocação de sua cultura e valores.

Outra questão seria a estruturação e ampliação dos parques urbanos, visto que a conexão entre o humano e a natureza é algo fundamental para o camponês. Neste ponto, pode-se indicar a importância do resgate dos rios, como local de visitação e permanência, formando grandes corredores nas cidades, onde isto for possível. A arborização das ruas e de espaços de convivência, trariam, também, para as cidades, maiores possibilidades de contato com a natureza, visto que daria margem para uma maior diversificação da fauna e da flora.

Visualizando-se que os movimentos sociais de luta por terra e moradia já vem trabalhando a questão da agroecologia e, que nas cidades, umas das ações de maior envergadura para dar resposta a suas demandas seria a implantação de conjuntos habitacionais de interesse social, é importante que estes espaços projetados pelo Estado considerem a necessidade de seu público camponês migrante, direcionando espaços adequados e apoiando a prática destas atividades. Neste caso, movimentos sociais poderiam 
dar continuidade a suas ações, através do acompanhamento e incentivo as práticas agroecológicas.

O que foi levantado aqui, nada mais é do que ideias para se considerar os camponeses como membros ativos nas cidades e, inseri-los, com suas demandas, visto as perdas que já trazem, pela problemática da questão agrária brasileira. Isto reforça o que Leonardo Boff traz no documentário "Resistir e Saber Cuidar": "a terra não é um meio de produção. A terra é um prolongamento do corpo na sua beleza, no seu entardecer, no seu florescer, é a casa comum, a casa viva". Nesta perspectiva, a moradia camponesa abrange aonde seu corpo alcança, no entrelaçamento entre ser humano e natureza. Não na separação entre as duas matérias, mas, na sua junção. Por isso, retirar o camponês da terra é amputá-lo, explorar seu trabalho é aprisioná-lo. E diante de tal questão, por que as cidades não poderiam abraçar a causa camponesa?

\section{Agradecimentos}

Ao Programa de Pós-Graduação em Arquitetura e Urbanismo da UFBA - PPGAU.

\section{REFERÊNCIAS}

ALCÂNTARA, Andréia Silva de. Ocupação Quilombo Paraíso: Moradia e Experiência Agroecológica na Cidade de Salvador/BA. Anais do IV SINARUB, Salvador, 2016.

DINIZ, Edite Luiz. Tapera, Pau Grande e Barreiros: Uma Geohistória de Resistência de Comunidades Tradicionais, no Litoral Norte da Bahia. (Dissertação de Mestrado) - Instituto de Geociências, Universidade Federal da Bahia, Salvador, 2007.

LIMA, Wéverson Fonseca; FONSECA, Wéverton José Lima; OLIVEIRA, Augusto Matias de; VOGADO, Gleissa Mayone Silva; SOUSA, Gioto Ghiarone Terto e; SOUSA, Tiago de Oliveira; SOUSA JÚNIOR, Severino Cavalcante de; LUZ, Carlos Syllas Monteiro. Causas e Consequências do Êxodo Rural no Nordeste Brasileiro. Nucleus, v.12, n., 2015 (2008).

JUNIOR, Valdemar João Wesz; ROTH, James Diego; MATTOS, Victor Mateus Menezes de; FERREIRA, Ana Margarete Rogrigues Martins; TRENTIN, Iran Carlos Lovis. Os Novos Arranjos do Exôdo Rural: A Evasão Temporária de Jovens Agricultores Familiares Gaúchos. Anais do XLIV Congresso da SOBER. "Questões Agrárias, Educação no Campo e Desenvolvimento", São Luiz Gonzaga (RS), 2006.

MARCOS, Valéria de; FABRINI, João Edmilson. Os Camponeses e a Práxis da Produção Coletiva. São Paulo: Expressão Popular, 2010. 
MOREIRA, P. A. M. S. Resistência e Territorializações: a Moradia Camponesa, com ênfase nos Projetos de Assentamento de Reforma Agrária do Estado da Bahia. (Tese de Doutorado) - PPGAU-FAUFBA, Salvador, 2017.

SANTOS, Milton. A urbanização Brasileira. 5. ed. SP: EDUSP, 2005.

SANTOS, Milton. Metamorfoses do Espaço Habitado. 6. ed. SP: EDUSP, 2014. SAQUET, Marcos Aurélio. Por uma Geografia das Territorialidades e das Temporalidades: Uma Concepção Multidimensional voltada para a Cooperação e para o Desenvolvimento Territorial. 2. ed. Rio de Janeiro: Consequência, 2015.

SCOOTT, James. Los Dominados y el Arte de la Resistencia: Discursos Ocultos. Tradução de Jorge Aguilar Moura. México: Ediciones ERA, 2008.

STÉDILE, João Pedro. A Questão Agrária no Brasil: o Debate Tradicional: 1500-1960. São Paulo: Expressão Popular, 2005.

VINHOLI, Ana Carolina; MARTINS, Pedro. Agricultura Urbana e Êxodo Rural. Revista de Ciências Sociais, volume 43, $\mathrm{n}^{\circ}{ }_{1}$. Fortaleza, 2012.

WANDERLEY, Maria de Nazareth Baudel; FAVARETO, Arilson. A Singularidade do Rural Brasileiro: Implicações para as Tipologias Territoriais e a Elaboração de Políticas Públicas. In: MIRANDA, Carlos; SILVA, Heithel (Orgs ). Concepções da Ruralidade Contemporânea: as singularidades brasileiras, contemporânea: as singularidades brasileiras. Brasília: IICA, 2013. (Série Desenvolvimento Rural Sustentável; v.21)

WOORTMANN, Klaas. Com parente não se neguceia: o campesinato como ordem moral. In: Anuário Antropológico/87, pp. 11-73. Brasília/Rio de Janeiro: Edunb: Tempo Brasileiro, 1990.

\section{Detalhes da autora}

Paula Adelaide Mattos Santos Moreira

Pesquisadora do Grupo de Pesquisa GeografAR/ IGEO/ UFBA. Doutora em Arquitetura e Urbanismo PPGAUUFBA. E-mail: paulagemeos@uol.com.br. 